\title{
Role of Angiotensin Peptides Precursor in Ethanol Mediated Hepato toxicity: Perspective on Angiotensinogen
}

\author{
Rais A. Ansari ${ }^{*}, 1$, Syed A. A. Rizvi ${ }^{1}$, Kazim Husain ${ }^{2}$ and Natalia Osna ${ }^{3}$ \\ ${ }^{1}$ Department of Pharmaceutical Sciences, College of Pharmacy, Health Professions Division, Nova Southeastern Uni- \\ versity, 3200 S University Drive, Fort Lauderdale, FL 33328, USA \\ ${ }^{2}$ Department of Physiology, Pharmacology and Toxicology, PO Box 7004, Ponce School of Medicine Ponce, PR 00732- \\ 7004, USA \\ ${ }^{3}$ Department of Internal Medicine, GI Section University of Nebraska Medical Center, VA Medical Center, 4101 Wool- \\ worth Ave, Omaha, NE 68105, USA
}

\begin{abstract}
Alcohol usage poses serious social and economical challenges. Its overuse is responsible for loss of billions of dollars due to fatal accidents and causes multiple diseases. Chronic alcoholism leads to liver disorders, including steatosis, hepatitis, fibrosis and cirrhosis. Both binge and chronic alcohol drinking result in blood pressure elevation and hypertension. As a significant mechanism, changes in the levels of angiotensinogen- released peptides play an important role in advanced alcohol liver disease. This review summarizes some of the studies that have demonstrated their role in liver fibrosis, cirrhosis and hypertension. Further, the individual variants and polymorphic sites may play a role in alcoholmediated regulation of angiotensinogen. Possible role of human angiotensinogen on alcohol hepatotoxicity is also discussed.
\end{abstract}

Keywords: Alcohol, toxicity, fibrosis, angiotensinogen, regulation, hypertension.

\section{INTRODUCTION}

Alcoholism leads to severe, often fatal liver diseases, and costs society many billions of dollars each year. Chronic alcohol consumption leads to hepatosteatosis, steatohepatitis, fibrosis, cirrhosis, as well as hypertension. Progression of hepatosteatosis and steatohepatitis to fibrosis and cirrhosis represents advanced stages of the alcohol liver disease [ALD]. ALD is the major cause of end-stage liver disease requiring liver transplantation to prevent death $[1,2]$. Sustained consumption of more than 2 drinks [30-50g ethanol] daily raises blood pressure [3-5]. Chronic alcoholism activates resident Kupffer cells and elevates cytokines levels such as tumor necrosis factor-alpha [TNF $\alpha]$ and interleukins, IL-1 $\beta$, IL-6, and IL-8 [2]. TNF $\alpha$ activates nuclear factorkappa B [NF-kB] signaling regulating hepatocyte death, while other cytokines activate hepatic stellate cells [HSC] leading to fibrosis and cirrhosis [6]. Studies have demonstrated that blocking the action of Angiotensin II [Ang II] provide protection against the progression of liver towards fibrosis and cirrhosis. In this review, we will focus on the role of Ang II and its precursor, angiotensinogen in alcoholmediated liver fibrosis, cirrhosis and hypertension.

There are many cellular and molecular events accompanying chronic ALD and hypertension. Fibrosis is initiated after parenchymal necrosis, followed by inflammation [7].

*Address correspondence to this author at the Department of Pharmaceutical Sciences, College of Pharmacy, Health Professions Division, Nova Southeastern University, 3200 S University Fort Lauderdale, FL 33328, USA; Tel: 954-262-1344; Fax: 954-262-2278; E-mail: ra557@nova.edu
Kupffer cells, the liver resident macrophages, are activated by increased circulating endotoxin. The endotoxin levels are enhanced by alcohol due to increased absorption from intestine after the death of gut bacteria. Activated Kupffer cells then secrete TGF- $\beta 1$, IL-1, IL-6, IL-8, and TNF $\alpha$ [8]. Cytokines activate HSCs, which increase collagen gene expression and expression of extracellular matrix molecules leading to fibrosis. Dying parenchymal cells induce inflammation, fibrosis, capillarization of sinusoids and increased extracellular matrix [ECMs] formation [9]. This causes elevated resistance and portal hypertension [10]. Depending upon the scale of injury, the host response is either restricted to HSC and Kupffer cells, or to a systemic acute phase response [APR], in which infiltration of immune cells occurs. In transformation of liver from steatohepatitis to fibrosis and cirrhosis, the renin-angiotensin system [RAS] plays a significant role. The production of active peptides from precursor, angiotensinogen involves both classical and alternate pathways. In a classical pathway, renin clips of N-terminal 10 amino acids [angiotensin I [Ang I]] from precursor AGT $[11,12]$. Ang I is converted into an octapeptide by clipping off 2 carboxyl terminal amino acids producing Ang II by angiotensin I converting enzyme [ACE]. Ang II is a biologically active endocrine hormone, which functions as a cytokine as well. In addition to classical pathways of production of Ang II, another homologue of ACE, ACE2 clips of one amino acid from carboxyl ends of Ang I to produce Ang 1-9 [13]. From Ang 1-9, Ang 1-7 is produced that possess opposite biological effects compared with Ang II [13-16]. Ang II can also be converted into Ang 1-7 by ACE2 [17, 18]. Similarly, Ang I and Ang 1-9 can be converted to Ang 1-7 [13]. 
Production of Ang 1-7 and its opposite biological effects as compared to Ang II constitutes another axis or alternate pathway of angiotensins action [16, 19, 20]. A schematic presentation of pathways for production of biologically active peptides from precursor AGT is depicted in Fig. (1).

Ang II binds to angiotensin type I and type II receptor [AT $\mathrm{AT}_{1}$ and $\left.\mathrm{AT}_{2} \mathrm{R}\right]$ while Ang 1-7 binds to Mas receptor which is an oncogene. Production of Ang 1-7 provides neuroprotective, cardioprotective, and hepatoprotective effects $[16,19,20]$. ACE2 also serves as the receptor of severe acute respiratory syndrome [SARS] virus glycoprotein [21] .

\section{PATHOPHYSIOLOGY}

In a diseased liver, the classical RAS [Ang II, $\mathrm{AT}_{1} \mathrm{R}$, renin and ACE] as well as alternative pathways [Ang 1-7, ACE2 and Mas receptor] are upregulated [6]. Ang II increases TGF- $\beta 1$ and ROS production in liver. TGF $\beta-1$ induces HSC activation, which activates further secretion of TGF $\beta-1$. Abrogation of Ang II effects offers protection against chemical and viral induced hepatic injury, and fibrosis. Blockade of Ang II pathway decreases carbon tetrachloride $\left[\mathrm{CCL}_{4}\right]$, the classical hepatotoxicant-induced fibrogenesis of the liver. AGT expression is increased in early stage of hepatic fibrosis in $\mathrm{CCL}_{4}$-induced liver fribrosis in rats [22]. Both local and circulating Ang II activation may mediate the response to liver injury $[23,24]$. In animal models of fibrosis and cirrhosis, blocking the production of Ang II from the precursor, angiotensin I [Ang I] by inhibiting ACE, protects the liver from becoming fibrotic $[6,8]$. Blocking the effects of Ang II at the $\mathrm{AT}_{1} \mathrm{R}$ level with selective inhibitors also blocks the fibrotic progression $[6,8]$. Animal models, in which the $\mathrm{AT}_{1} \mathrm{R}$ is knocked out, are resistant to fibrosis and cirrhosis $[25,26]$. Systemic infusion of Ang II increases bile duct blockade-mediated liver fibrosis [27]. A pilot study evaluating efficacy of the $\mathrm{AT}_{1} \mathrm{R}$ blocker [ARB], losartan provided protective effects against hepatitis $\mathrm{C}$-induced fibrosis $[28,29]$. Another ARB, candesartan, improved one fibrotic marker, while it exhibited no effect on three other markers in a 48-week trial of cirrhotic children [30]. Ang II is also implicated in non-alcoholic fatty liver disease via oxidative stress in Ren2 transgenic rats [31]. RAS blockers have anti-fibrotic and anti-cirrhotic potential in hepatitis $\mathrm{C}$ and liver transplant patients [32-34]. Role of ACE2 in blocking the development of liver fibrosis is encouraging. Experimental studies demonstrate that ACE2 activation inhibits liver fibrosis in mice. It seems that there is a balance between ACE and ACE2 activities and outcome of liver for fibrosis depends upon these activities $[35,36]$. In other studies, urinary level of AGT has been linked to severity of chronic kidney disease. It has been found with human patients that urinary AGT levels correlate to kidney function and increased levels correlate to tubular atrophy, glomeruloscerosis and tubular fibrosis [37]. Studies with animals demonstrate that urimic toxins, indoxyl sulphate and p-cresol sulphate activate intrarenal renin-angiotensin-aldosterone system causing increased angiotensinogen expression including other fibrogenic markers [38]. Over expression of catalase which removes oxidative stress prevents hypertension and kidney tubular apoptosis in angiotensinogen transgenic mice [39]. Trancriptional activation of AGT, also plays a significant role in lung fibrogenesis [40].

In addition to its role in hepatoxicant-mediated fibrosis and cirrhosis, the RAS plays a major role in hydromineral
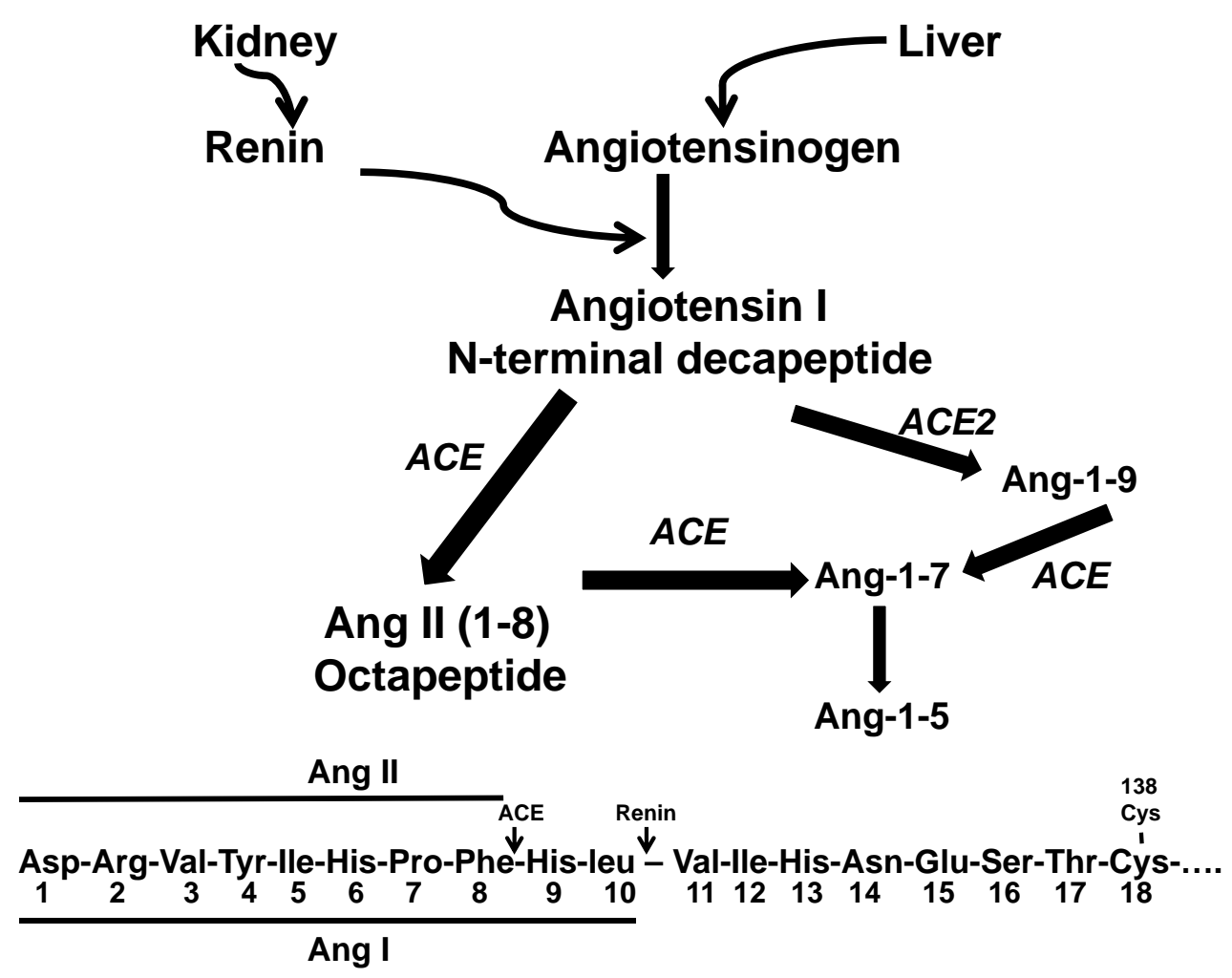

Fig. (1). Production of biologically active peptides from precursor angiotensinogen. 
and cardiovascular homeostatis [41]. The octapeptide, Ang II is a potent vasopressor molecule [42]. The primary source of circulating AGT is the liver. The synthesis and secretion of angiotensinogen [AGT] occurs in liver while it is synthesized in extrahepatic tissues and organs. The circulating plasma concentration of AGT is less than saturating concentration of aspartyl protease, renin $[<$ Michaelis-Menten constant $\left.\left[K_{m}\right]\right]$ [43]. Alterations in circulating AGT levels lead to corresponding changes in the level of Ang II. Therefore, an increase in the circulating AGT level can increase blood Ang II levels. The ability of AGT to produce corresponding level of Ang II links AGT to hypertension [44-46]. Published reports also indicate direct relation between AGT and blood pressure. For instance, a highly significant relationship between plasma concentration of AGT and blood pressure in human subjects [44], higher plasma AGT levels in hypertensive subjects and in offspring of hypertensive parents compared against normotensives [44, 46], expression of AGT gene in multiple tissues and organs are directly involved in blood pressure regulation [47], Moreover, increase in blood pressure is observed in transgenic animals that over-express AGT gene [45, 48, 49], while, lowering of blood pressure in AGT gene knockout mice has also been observed [45]. Increasing copy number of AGT up to four copies in mice, causes successive increases in blood pressure [48]. These results invariably demonstrate that small changes in plasma AGT level can quantitatively influence and alter blood pressure in a gene dose dependent manner. On the other hand, a similar ACE gene duplication in mice increases plasma ACE level with no effect on blood pressure [50].

Variations among genes often have been linked to varied responses to drug therapy and detoxification and hAGT is no exception. Jeunemaitre et. al. were the first authors to show a direct role of angiotensinogen gene in essential hypertension [51]. They had shown that variant M235T [methionine at 235 substituted by threonine] is associated with essential hypertension and increased plasma AGT levels in hypertensive patients. These studies were later confirmed by Caulfield et al in Caucasian and African-Carribean hypertensive families $[52,53]$. Since amino acid $235 \mathrm{~T}$ is the part of the coding region of AGT protein, this polymorphism does not explain mechanism involved in increased plasma AGT levels. Human AGT possesses several polymorphic sites. It has an $\mathrm{A} / \mathrm{G}$ polymorphism at nucleoside -6 . It has been shown that nucleoside A at -6 is present in the ancestral AGT and the reporter assays with nucleoside A at -6 with hAGT promoter exhibits increased promoter activity compared to nucleoside $\mathrm{G}$ at -6 . The molecular variants $235 \mathrm{~T}$ and $-6 \mathrm{~A}$ are in linkage disequilibrium [54]. This observation shows that increased plasma AGT levels by polymorphism M235T in hypertensive patients may actually be due to, possibly, increased transcriptional activity of the human AGT by -6A nucleoside. However, the transcriptional regulation by $-6 \mathrm{~A}$ nucleoside as compare to $-6 \mathrm{G}$ is not known. Nevertheless, the transgenic studies demonstrate that this polymorphism neither changes the expression of the AGT nor increases blood pressure [55]. In conclusion, inhibition of the RAS in experimental animals and clinical studies has proven effective in counteracting fibrosis, cirrhosis, and hypertension [6, 13, 14, 16]. Thus the involvement of Ang II in fibrosis, cir- rhosis and hypertension, puts the precursor AGT in a critical role.

\section{MOLECULAR EVENTS OF ETHANOL TOXICITY}

\section{Activation of Transcription Factors}

Fatty liver [steatosis] is the earliest, most common response of the liver to moderate or large doses/binge drinking of alcohol, as well as chronic ethanol abuse [56]. Hepatic fatty acid and triglycerides are increased after acute and chronic ethanol consumption [57]. Utilizing cell-based model, increased lipogenesis has been shown to occur due to higher expression and activation of lipogenic enzymes [58, 59]. The lipogenic enzymes are under regulation of sterol regulatory element binding protein [SREBP]. SREBPs are a class of transcription factors which are involved in fat and cholesterol regulation. There are three isoforms of SREBPs, SREBP-1a, SREBP-1c and SREBP-2. Both SREBP-1a and $1 \mathrm{c}$, which are alternate spliced forms, are involved in regulation of fatty acid biosynthesis. SREBPs exist as precursor molecules in endoplasmic reticulum and are activated by SREBP cleavage activating protein [SCAP] and site-1 protease $[\mathrm{S} 1 \mathrm{P}]$ and site- 2 protease $[\mathrm{S} 2 \mathrm{P}]$ and their activation is dependent on the cellular cholesterol level. Studies have demonstrated that ethanol exposure of cultured cells leads to increased level of active/nuclear form of SREBP-1 [nSREBP-1]. SREBP activation is dependent on alcohol metabolism and the metabolic product, acetaldehyde is capable of activation of SREBP-1 and the inhibitors of alcohol dehydrogenase [4-methylpyrazole] blocked the SREBP activation in cultured rat hepatocytes and HepG2 cells [60, 61]. SREBP-1c level is increased transcriptionally and by decreased proteasomal degradation of protein in acute and chronic alcohol exposure [62].

Alcohol exposure causes increased gut permeability of endotoxin, which stimulates production of proinflammatory, tumor necrosis factor- $\alpha[\mathrm{TNF} \alpha]$ and cytoprotective cytokines [interleukin-6 and 10] from Kupffer's cells, the resident macrophages. The level of TNF $\alpha$ is increased in chronic alcohol abusers and animal models of alcohol toxicity. The level of interleukins, [IL-1, IL-6 and IL-8] has been found increased in hospitalized patient with ALD and in animal models of alcohol toxicity [63-65]. The increase in IL-6 due to ethanol in patients is the part of the hepatoprotective process. IL-6 and IL-10 activate signal transducer and activator of transcription [STAT3], which is responsible for liver regeneration and provides protection against redox-dependent cell death $[66,67]$. Activation of STAT3 causes induction of anti-inflammatory signal to inhibit inflammation during alcohol mediated injury [63]. Hepatic knock out of STAT3 in mice increases hepatosteatosis and increased expression of lipogenic genes after ethanol exposure [68].

Recent studies have demonstrated that adenosine monophosphate activated protein kinase [AMPK] is centrally involved in the regulation of hepatic triglycerides, cholesterol and the fatty acid biosynthesis, which is under the transcriptional regulation of SREBP-1. Recently, it has been established that SREBP-1 is the target of AMPK [69]. Activation of AMPK in hepatocytes caused decreased nSREBP-1 level due to increased proteasomal degradation [70]. Metformin and aminoimidazole-4-carboxamide ribonucleotide [AICAR] 
are known activators of AMPK and treatment of hepatoma cells results in decreased nSREBP while ethanol treatment reversed the effects [70]. Therefore, AMPK can play a significant role in ethanol mediated effect on hepatic SREBP-1. This finding has been further substantiated by a recent report that fat derived hormone, adiponectin which is upregulated in ethanol exposure, down regulates AMPK, alleviating alcoholic fatty liver disease [71]. In addition to regulation of lipogenic genes via SREBP-1, ethanol has been shown to alter liver activating protein [LAP] and liver inhibiting protein [LIP] in rats chronically fed with ethanol. Both LAP and LIP are basic helix loop helix transcription factor which bind to CAAT sequences in DNA and are referred as CAAT/enhancer binding protein [C/EBP]. LAP is a full length C/EBP$\beta$ which activates liver specific transcription of genes. LIP is the short form of C/EBP- $\beta$ and inhibits hepatic gene transcription. C/EBPs are activated in endoplasmic reticulumstress [ER-Stress] and alcohol exposure produces ER-stress $[72,73]$. Chronic ethanol exposure in rats causes increase in LAP [C/EBP- $\beta]$ and reduction in LIP in liver and this increase in LAP vs LIP is responsible for ethanol induced effects [increase] on Class I alcohol dehydrogenase in liver [74].

\section{Oxidative Stress and Cellular Protection}

Ethanol is metabolized enzymatically in four compartments: cytosol [alcohol dehydrogenase], mitochondria [aldehyde dehydrogenase], microsome [CYP 2E1] and peroxisome [catalase]. Chronic ethanol ingestion has been shown to induce hepatic CYP2E1 leading to generation of 1hydroxy ethyl radical. The hepatic oxidative stress relates to induction of reactive oxygen species [ROS] formation and down-regulation of antioxidant enzymes; superoxide dismutase [SOD], catalase [CAT], and glutathione peroxidase [GPX] and endogenous antioxidant, glutathione [75, 76]. Mild to moderate alcohol usage leads to increased hepatic
iron-II $\left[\mathrm{Fe}^{++}\right]$levels [77]. The increased $\mathrm{Fe}^{++}$occurs in Kupffer cells in animal model of ALD $[78,79] . \mathrm{Fe}^{++}$and alcohol metabolism in the liver by CYP2E1 produce ROS and hypoxia [80]. Activation of hypoxia-inducible transcription factor-1alpha [HIF-1 $\alpha$ ] has been observed with ethanol exposure in control and with hepcidin, an iron sensing peptide knockout mice [81, 82]. ROS causes oxidative stress in ethanol metabolizing cells; especially hepatocytes. Reducing ROS is linked to cytoprotection and cell survival. Induction of cytoprotective enzymes in response to increased ROS is regulated at the transcriptional level by a cis-acting antioxidant response element [ARE] after binding of nuclear factor erythroid2-related factor2 [Nrf2]. Initially, ARE sequences were defined with two detoxifying enzymes, glutathione Stransferase $\mathrm{A}_{2}$ and NADPH:quinone oxidoreductase [83]. Regulation of genes via ARE involves the activation of Nrf2 which remains in inactive form in cytoplasm and relocates to nucleus upon activation $[84,85]$. Activation of hypoxia inducible transcription factor-1alpha [HIF-1 $\alpha$ ] is observed in hypoxic and increased ROS states [86]. After activation, HIF- $1 \alpha$ activates and/or represses the genes containing hypoxia response element [HRE] [87]. Fatty acid synthase [FAS] gene which is responsible for lipogenesis is upregulated in alcohol exposure as well as in tumor cells which possess hypoxic microenvironments. [88]. The sequence of events of alcohol exposure and its effects are summarized in Table 1.

ROS stimulated expression of AGT in renal cells occurs with $\operatorname{IgA}$ induced nephropathy in high serum IgA [HIGA] mice [89]. Activation of AGT by ROS secondary to high glucose levels has also been observed in rat kidney proximal tubule [90]. The level of AGT mRNA increases with binge ethanol exposure [91]. Thus it is becoming evident that ethanol exposure and increased ROS activate AGT transcription. In an animal model, it ha been shown that the level of Ang II is increased which corresponds to oxidative stress in endothelial cells in rats exposed to ethanol $[92,93]$. Utilizing the

Table 1. Sequence of Events after Ethanol Exposure

\begin{tabular}{|c|c|c|}
\hline Order of Events & Alcohol-Exposure & Alcohol-Metabolism \\
\hline Initial & $\begin{array}{l}\text { Death of gut bacteria } \\
\text { Release of Lipopolysaccharide } \\
\text { [endotoxin from gram negative bacteria] }\end{array}$ & $\begin{array}{l}\text { Acetaldehyde, NADH and Reactive oxygen species [ROS] for- } \\
\text { mation }\end{array}$ \\
\hline Subsequent & $\begin{array}{l}\text { Activation of local [Kupffer cell] or systemic immune response } \\
\text { due to liver injury }\end{array}$ & $\begin{array}{l}\text { Acetylation of hepatocyte protein } \\
\text { Increased lipid biosynthesis } \\
\text { Oxidative stress }\end{array}$ \\
\hline Subsequent & Release of cytokines [TNF $\alpha$ ], IL-1 $\beta$, IL- 6 , IL-8 etc. & Hepatocyte death due to oxidative stress and TNF $\alpha$ \\
\hline Subsequent & Activation of Stellate cells & Process starts for replacement of dead hepatocytes \\
\hline Subsequent & $\begin{array}{l}\text { Stellate cells secrete TGF- } \beta 1 \text {, starts fibrotic process by synthesiz- } \\
\text { ing the extracellular matrix molecules }\end{array}$ & Hepatocytes replaced with fibrotic tissue [fibrosis] \\
\hline Subsequent & $\begin{array}{l}\text { Release of cytokines for repair process } \\
\text { Participation of angiotensin II in repair }\end{array}$ & $\begin{array}{l}\text { Constriction of sinusoids, synthesis for replacement of tissues } \\
\text { around portal vein produce constriction }\end{array}$ \\
\hline Subsequent & & Portal hypertension, scar tissue formation [cirrhosis], liver failure \\
\hline
\end{tabular}


cell based model, our lab has demonstrated increased AGT secretion from human hepatocytes [94, 95].The critical question of AGT activation is how these events regulate the hAGT gene during ethanol toxicity.

\section{REGULATION OF HUMAN ANGIOTENSINOGEN AND POSSIBLE ETHANOL EFFECTS}

The human AGT gene promoter is located 5'-upstream of the coding sequences while the enhancer region is located at 3' downstream [96] . The human AGT gene proximal promoter nucleotide sequences -1223 to +27 is defined for the possible cis-acting DNA response element for the different transcription factors as shown in Fig. (2). Some of the studies which have been carried out from Kumar lab and others have defined the role of transcription factors which are involved in the regulation of organ specific AGT expression [97]. CAAT enhancer binding protein [C/EBP] family of transcription factors especially $\mathrm{C} / \mathrm{EBP} \beta$ binds to the sequences at -99 to -91 of human AGT gene promoter [98] . In addition, liver specific transcription factor HNF3 binds to the sequences located between +10 and +20 of human gene AGT promoter [99]. Human AGT gene is type II acute phase response protein secreted by liver. Accordingly, there are three sites of acute phase response element [APRE] and one of them is at $-278 /-269$, where IL-6 induced STAT3 binding is responsible for IL-6 induced effects [100]. The differences in the mouse and human AGT promoters are in the APRE. While the mouse AGT is a type I APR and is induced by IL1 via NF- $\mathrm{KB}$ while human AGT is induced by IL-6 via STAT3 [101]. In addition to these defined sites, CREB site is located at -840 and -830 of human AGT and this element is responsible for the cAMP induced effects on human AGT expression [102] . There are at least 3 direct repeats [DRs] sequences in human AGT. DR1 is located between -363 and -423 and is the binding site for HNF4 and HNF4 is capable of binding and expression of human AGT by DR1 [103]. Glucocorticoids play a significant role in the expression of human AGT gene since it is an APR II gene. There are a number [3] of half glucocorticoid response element [GRE [$673,-130$ and +15$]]$ and one full GRE at -217 position. Due to the single nucleotide polymorphism [SNP] at $-217[\mathrm{~A} / \mathrm{G}]$, the -217 position with A substitution becomes a complete palindromic site for GR. The role of GR in transcriptional regulation of human AGT by -217A polymorphism has been demonstrated by Jain et al [104]. The hierarchal regulation of AGT by glucocorticoids observed in mouse is not well defined for human AGT besides the presence of multiple GREs [101] . Similarly, the SNPs at -6 [G/A] and -20 [C/A] also result into binding site for the transcription factor. The 20A SNP leads to the creation of SP1 site and is modulated by estrogen receptor. Orphan nuclear receptor, Arp-1 also binds to the sequences and is capable of disrupting the ER induced effects [105]. In addition to the aforementioned SNP and its significance in the transcriptional regulation of human AGT, a number of other SNPs [-1074 T/G, -793 A/G and $-776 \mathrm{C} / \mathrm{T}]$ have also been reported. SNP $-1074 \mathrm{~T}$ binds to HNF3 $\beta$ while $-1074 \mathrm{G}$ lacks the binding ability [97].

\section{CLINICAL SIGNIFICANCE}

Polymorphic site -217 A has been shown to bind CEBP- $\beta$ and glucocorticoids. Similarly, $-1074 \mathrm{~T}$ binds with hepatocyte nuclear factor- $3 \beta$. As mentioned above that alcohol exposure increases the ratio of LAP vs LIP. Increasing activity of LAP after ethanol exposure is likely to increase the transcription of hAGT. Individuals possessing the $-1074 \mathrm{~T}$ variant may contain increased level of AGT as HNF-3 $\beta$ is liver specific transcription factor. HNF-3 $\beta$ is an orphan transcription factor whose modulation by agonist is not well characterized. SNP6/A is in linkage disequilibrium with M235T. The role of $6 \mathrm{~A}$ has been shown to possess higher promoter activity but its mechanism is not known. It is known that individuals with 235T possess increased level of circulating AGT [51]. Studies relating to linkage disequilibrium have observed that SNP -6A, -217A, -776T, -793A and -1074T are in association. Due to higher levels of AGT mediated by $-6 \mathrm{~A},-216 \mathrm{~A}$, $1074 \mathrm{~T}$, it is anticipated that these individuals will carry in-
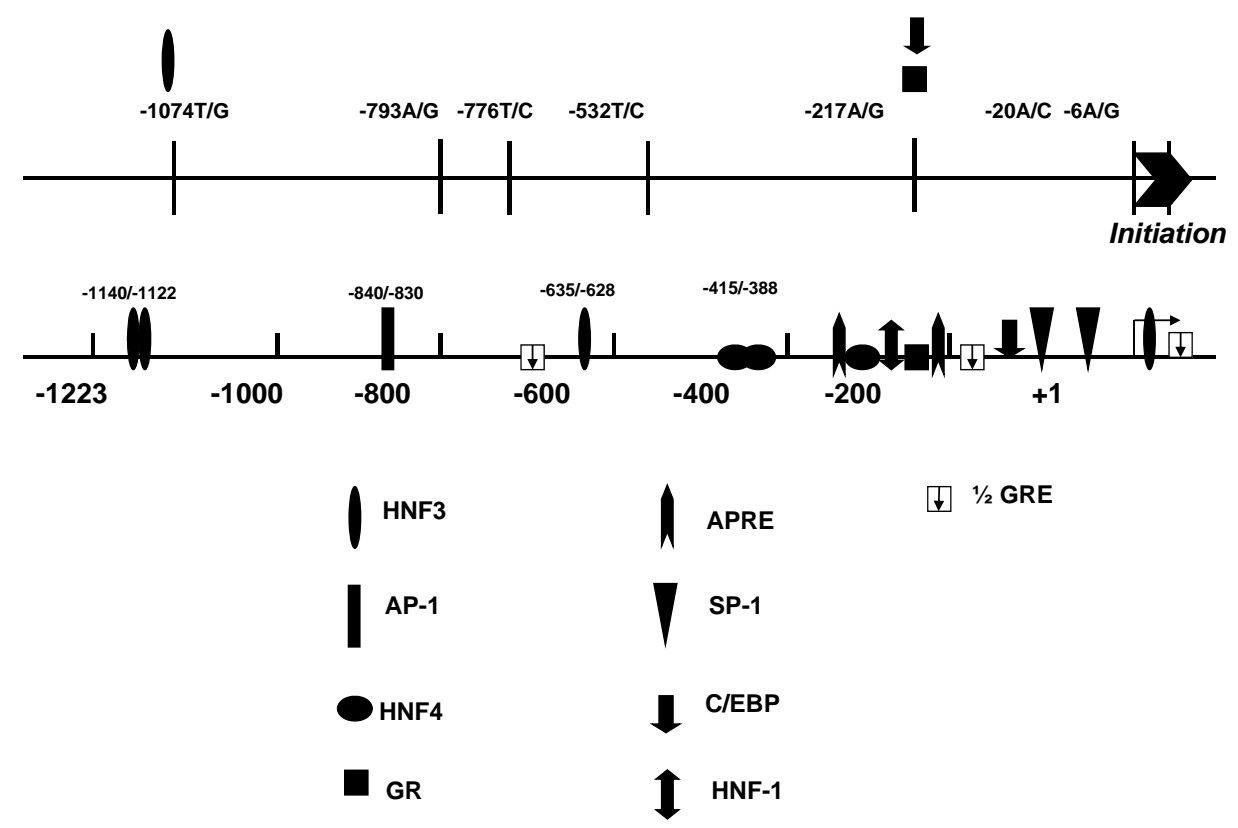

Fig. (2). Human AGT proximal promoter structure and single nucleotide polymorphic sites binding site to possible transcription factors. 


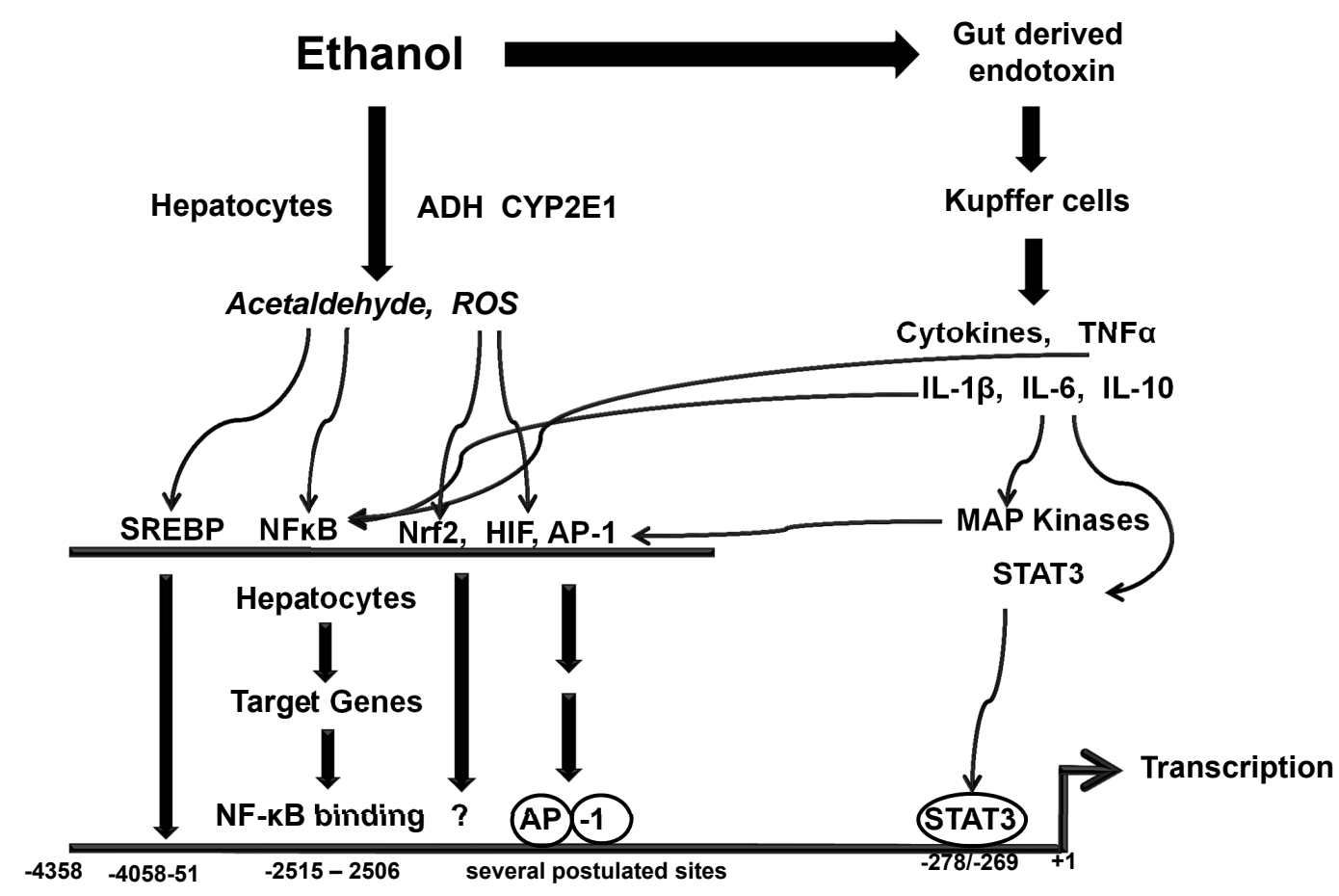

Fig. (3). Ethanol mediated activation and role of transcription factors in regulation of human angiotensinogen gene.

creased risk of alcohol mediated hepatotoxicity and alcohol mediated hypertension due to possible increase in circulating AGT level.

AGTs are acute phase response proteins. While mouse and rat AGT are acute phase response type I proteins, human AGT is APR type II proteins. In injured and inflammed liver, this organ responds to the cascade activation of APRs. In APR I, liver secretes a set of proteins which is followed by APR II in which another sets of proteins are released. In APR, the level of secreted proteins either increases or decreases. In APR, the level of AGT increases while albumin decreases [106-108]. Mouse and rat AGT are classified as APR I proteins because they response to nuclear factorkappB $[\mathrm{NF}-\kappa \mathrm{B}]$ by tumor necrosis factor-alpha $[\mathrm{TNF} \alpha]$ and interleukin-1beta [IL-1 $\beta$ ]. APR II proteins are responsive to IL-6 and glucocorticoids. Human AGT was known not to possess NF- $\kappa \mathrm{B}$ binding site in the proximal promoter and hence its regulation by TNF $\alpha$ and IL- $1 \beta$ were unknown. Recently, a NF- $\kappa \mathrm{B}$ binding site has been reported in the distal promoter of hAGT which is responsive to NF- $\mathrm{kB}$ activity in kidney epithelial cells [109]. In case of either binge or chronic alcohol intake, either local response to Kupffer's cell or systemic response due to infiltration of immune cells to liver, the level of TNF $\alpha$ and IL-1 $\beta$ is increased.

In patients suffering from chronic alcoholism the levels of aforementioned cytokines are increased in the blood. Due to increase in these cytokines, the synthesis and secretion of AGT from hepatocytes are likely to increase. Cytokine, IL-6 activates signal transducer and activator of transcritption [STAT3] which activates AGT transcription by binding to APR site of hAGT promoter at $-278 /-269$. Activation of STAT3 occurs due to increased circulating level of IL-6 among chronic alcoholics. The binding site[s] of SREBP, a transcription factor which is increased in hepatocytes after ethanol exposure, has not been established. A TRANSFAC analysis indicate presence of SREBP binding site. Alcohol mediated increase in CEBP/ $\beta$, SREBP, and activation of NF$\mathrm{kB}, \mathrm{HIF}-1 \alpha$, and Nrf2 are likely to affect hAGT transcription in liver and affect [increase] its synthesis and secretion thereby affecting the alcohol mediated liver fibrosis and hypertension as depicted in Fig. (3).

\section{CONFLICT OF INTEREST}

The author(s) confirm that this article content has no conflicts of interest.

\section{ACKNOWLEDGEMENT}

None declared.

\section{REFERENCES}

[1] Altamirano J, Bataller R. Alcoholic liver disease: pathogenesis and new targets for therapy. Nat Rev Gastroenterol Hepatol 2011; 8(9): 491-501.

[2] Gao B, Bataller R. Alcoholic liver disease: pathogenesis and new therapeutic targets. Gastroenterology 2011; 141(5): 1572-85.

[3] Chen L, Davey Smith G, Harbord RM, Lewis SJ. Alcohol intake and blood pressure: a systematic review implementing a Mendelian randomization approach. PLoS Med 2008; 5(3): e52.

[4] Hillbom M, Saloheimo P, Juvela S. Alcohol consumption, blood pressure, and the risk of stroke. Curr Hypertens Rep 2011; 13(3): 208-13.

[5] Zilkens RR, Burke V, Hodgson JM, Barden A, Beilin LJ, Puddey IB. Red wine and beer elevate blood pressure in normotensive men. Hypertension 2005; 45(5): 874-9.

[6] Lubel JS, Herath CB, Burrell LM, Angus PW. Liver disease and the renin-angiotensin system: recent discoveries and clinical implications. J Gastroenterol Hepatol 2008; 23(9): 1327-38.

[7] Bruha R, Dvorak K, Petrtyl J. Alcoholic liver disease. World J Hepatol 2012; 4(3): 81-90.

[8] Pereira RM, Dos Santos RA, Teixeira MM, et al. The reninangiotensin system in a rat model of hepatic fibrosis: evidence for a 
protective role of Angiotensin-[1-7]. J Hepatol 2007; 46(4): 67481.

[9] Friedman SL. Mechanisms of hepatic fibrogenesis. Gastroenterology 2008; 134(6): 1655-69.

[10] Lubel JS, Angus PW. Modern management of portal hypertension. Intern Med J 2005; 35(1): 45-9.

[11] Campbell DJ. Tissue renin-angiotensin system: sites of angiotensin formation. J Cardiovasc Pharmacol 1987; 10 (Suppl). 7: S1-8.

[12] Lavoie JL, Sigmund CD. Minireview: overview of the reninangiotensin system--an endocrine and paracrine system. Endocrinology $2003 ; 144(6): 2179-83$.

[13] Pereira RM, dos Santos RA, da Costa Dias FL, Teixeira MM, Simoes e Silva AC. Renin-angiotensin system in the pathogenesis of liver fibrosis. World J Gastroenterol 2009; 15(21): 2579-86.

[14] Huang ML, Li X, Meng Y, et al. Upregulation of angiotensinconverting enzyme $[\mathrm{ACE}] 2$ in hepatic fibrosis by ACE inhibitors. Clin Exp Pharmacol Physiol 2010; 37(1): e1-6.

[15] Munshi MK, Uddin MN, Glaser SS. The role of the reninangiotensin system in liver fibrosis. Exp Biol Med [Maywood] 2011; 236(5): 557-66.

[16] Vilas-Boas WW, Ribeiro-Oliveira A Jr., Pereira RM, et al. Relationship between angiotensin-[1-7] and angiotensin II correlates with hemodynamic changes in human liver cirrhosis. World J Gastroenterol 2009; 15(20): 2512-9.

[17] Eriksson U, Danilczyk U, Penninger JM. Just the beginning: novel functions for angiotensin-converting enzymes. Curr Biol 2002; 12(21): R745-52.

[18] Rice GI, Thomas DA, Grant PJ, Turner AJ, Hooper NM. Evaluation of angiotensin-converting enzyme [ACE], its homologue ACE2 and neprilysin in angiotensin peptide metabolism. Biochem J 2004; 383(Pt 1): 45-51.

[19] Nguyen Dinh Cat A, Touyz RM. A new look at the reninangiotensin system--focusing on the vascular system. Peptides 2011; 32(10): 2141-50.

[20] Zimmerman MC. Angiotensin II and angiotensin-1-7 redox signaling in the central nervous system. Curr Opin Pharmacol 2011; 11(2): 138-43.

[21] Beniac DR, deVarennes SL, Andonov A, He R, Booth TF. Conformational reorganization of the SARS coronavirus spike following receptor binding: implications for membrane fusion. PLoS One 2007; 2(10): e1082.

[22] Lu P, Liu H, Yin H, Yang L. Expression of angiotensinogen during hepatic fibrogenesis and its effect on hepatic stellate cells. Med Sci Monit 2011; 17(9): BR248-56.

[23] Brenner DA, Westwick J, Breindl M. Type I collagen gene regulation and the molecular pathogenesis of cirrhosis. Am J Physiol 1993; 264(4 Pt 1): G589-95.

[24] Kanzler S, Lohse AW, Keil A, et al. TGF-beta1 in liver fibrosis: an inducible transgenic mouse model to study liver fibrogenesis. Am J Physiol 1999; 276 (4 Pt 1): G1059-68.

[25] Nabeshima Y, Tazuma S, Kanno K, et al. Anti-fibrogenic function of angiotensin II type 2 receptor in CCl4-induced liver fibrosis. Biochem Biophys Res Commun 2006; 346(3): 658-64.

[26] Yang L, Bataller R, Dulyx J, et al. Attenuated hepatic inflammation and fibrosis in angiotensin type 1a receptor deficient mice. J Hepatol 2005; 43(2): 317-23.

[27] Bataller R, Gabele E, Parsons CJ, et al. Systemic infusion of angiotensin II exacerbates liver fibrosis in bile duct-ligated rats. Hepatology 2005; 41(5): 1046-55.

[28] Wei YH, Jun L, Qiang CJ. Effect of losartan, an angiotensin II antagonist, on hepatic fibrosis induced by CCl4 in rats. Dig Dis Sci 2004; 49(10): 1589-94.

[29] Yoshiji H, Noguchi R, Ikenaka Y, et al. Losartan, an angiotensin-II type 1 receptor blocker, attenuates the liver fibrosis development of non-alcoholic steatohepatitis in the rat. BMC Res Notes 2009; 2: 70 .

[30] Debernardi-Venon W, Martini S, Biasi F, et al. AT1 receptor antagonist Candesartan in selected cirrhotic patients: effect on portal pressure and liver fibrosis markers. J Hepatol 2007; 46(6): 102633.

[31] Wei Y, Clark SE, Morris EM, et al. Angiotensin II-induced nonalcoholic fatty liver disease is mediated by oxidative stress in transgenic TG[mRen2]27[Ren2] rats. J Hepatol 2008; 49(3): 41728.

[32] Rimola A, Londono MC, Guevara G, et al. Beneficial effect of angiotensin-blocking agents on graft fibrosis in hepatitis $\mathrm{C}$ recur- rence after liver transplantation. Transplantation 2004; 78(5): 68691.

[33] Terui Y, Saito T, Watanabe H, et al. Effect of angiotensin receptor antagonist on liver fibrosis in early stages of chronic hepatitis $\mathrm{C}$. Hepatology 2002; 36(4 Pt 1): 1022.

[34] Yoshiji H, Noguchi R, Fukui H. Combined effect of an ACE inhibitor, perindopril, and interferon on liver fibrosis markers in patients with chronic hepatitis C. J Gastroenterol 2005; 40(2): 215-6.

[35] Osterreicher $\mathrm{CH}$, Taura $\mathrm{K}$, De Minicis S, et al. Angiotensinconverting-enzyme 2 inhibits liver fibrosis in mice. Hepatology 2009; 50(3): 929-38.

[36] Warner FJ, Lubel JS, McCaughan GW, Angus PW. Liver fibrosis: a balance of ACEs? Clin Sci [Lond] 2007; 113(3): 109-18.

[37] Kim SM, Jang HR, Lee YJ, et al. Urinary angiotensinogen levels reflect the severity of renal histopathology in patients with chronic kidney disease. Clin Nephrol 2011; 76(2): 117-23.

[38] Sun CY, Chang SC, Wu MS. Uremic Toxins Induce Kidney fibrosis by activating intrarenal renin-angiotensin-aldosterone system associated epithelial-to-mesenchymal transition. PLoS One 2012; 7(3): e34026.

[39] Godin N, Liu F, Lau GJ, et al. Catalase overexpression prevents hypertension and tubular apoptosis in angiotensinogen transgenic mice. Kidney Int 2012; 77(12): 1086-97.

[40] Uhal BD, Dang MT, Li X, Abdul-Hafez A. Angiotensinogen gene transcription in pulmonary fibrosis. Int J Pept 2012; 2012: 875910.

[41] Unger T. The angiotensin type 2 receptor: variations on an enigmatic theme. J Hypertens 1999; 17(12 Pt 2): 1775-86.

[42] Corvol P, Jeunemaitre X. Molecular genetics of human hypertension: role of angiotensinogen. Endocr Rev 1997; 18(5): 662-77.

[43] Gould AB, Green D. Kinetics of the human renin and human substrate reaction. Cardiovasc Res 1971; 5(1): 86-9.

[44] Fasola AF, Martz BL, Helmer OM. Renin activity during supine exercise in normotensives and hypertensives. J Appl Physiol 1966; 21(6): 1709-12.

[45] Tanimoto K, Sugiyama F, Goto Y, et al. Angiotensinogen-deficient mice with hypotension. J Biol Chem 1994; 269(50): 31334-7.

[46] Watt GC, Harrap SB, Foy CJ, et al. Abnormalities of glucocorticoid metabolism and the renin-angiotensin system: a four-corners approach to the identification of genetic determinants of blood pressure. J Hypertens 1992; 10(5): 473-82.

[47] Campbell DJ, Habener JF. Angiotensinogen gene is expressed and differentially regulated in multiple tissues of the rat. J Clin Invest 1986; 78(1): 31-9.

[48] Kim HS, Krege JH, Kluckman KD, et al. Genetic control of blood pressure and the angiotensinogen locus. Proc Natl Acad Sci USA 1995; 92(7): 2735-9.

[49] Kimura S, Mullins JJ, Bunnemann B, et al. High blood pressure in transgenic mice carrying the rat angiotensinogen gene. EMBO J 1992; 11(3): 821-7.

[50] Krege JH, Kim HS, Moyer JS, et al. Angiotensin-converting enzyme gene mutations, blood pressures, and cardiovascular homeostasis. Hypertension 1997; 29(1 Pt 2): 150-7.

[51] Jeunemaitre X, Soubrier F, Kotelevtsev YV, et al. Molecular basis of human hypertension: role of angiotensinogen. Cell 1992; 71(1): $169-80$.

[52] Caulfield M, Lavender P, Newell-Price J, et al. Linkage of the angiotensinogen gene locus to human essential hypertension in African Caribbeans. J Clin Invest 1995; 96(2): 687-92.

[53] Caulfield M, Lavender P, Newell-Price J, Kamdar S, Farrall M, Clark AJ. Angiotensinogen in human essential hypertension. Hypertension 1996; 28(6): 1123-5.

[54] Inoue I, Nakajima T, Williams CS, et al. A nucleotide substitution in the promoter of human angiotensinogen is associated with essential hypertension and affects basal transcription in vitro. J Clin Invest 1997; 99(7): 1786-97.

[55] Cvetkovic B, Keen HL, Zhang X, Davis D, Yang B, Sigmund CD. Physiological significance of two common haplotypes of human angiotensinogen using gene targeting in the mouse. Physiol Genomics 2002; 11(3): 253-62.

[56] Zhou Z, Wang L, Song Z, Lambert JC, McClain CJ, Kang YJ. A critical involvement of oxidative stress in acute alcohol-induced hepatic TNF-alpha production. Am J Pathol 2003; 163(3): 1137-46.

[57] Lieber CS, Savolainen M. Ethanol and lipids. Alcohol Clin Exp Res 1984; 8(4): 409-23.

[58] Carrasco MP, Jimenez-Lopez JM, Segovia JL, Marco C. Comparative study of the effects of short- and long-term ethanol treatment 
and alcohol withdrawal on phospholipid biosynthesis in rat hepatocytes. Comp Biochem Physiol B Biochem Mol Biol 2002; 131(3): 491-7.

[59] Carrasco MP, Marco C, Segovia JL. Chronic ingestion of ethanol stimulates lipogenic response in rat hepatocytes. Life Sci 2001; 68(11): 1295-304.

[60] Lluis JM, Colell A, Garcia-Ruiz C, Kaplowitz N, Fernandez-Checa JC. Acetaldehyde impairs mitochondrial glutathione transport in HepG2 cells through endoplasmic reticulum stress. Gastroenterology 2003; 124(3): 708-24.

[61] You M, Fischer M, Deeg MA, Crabb DW. Ethanol induces fatty acid synthesis pathways by activation of sterol regulatory elementbinding protein [SREBP]. J Biol Chem 2002; 277(32): 29342-7.

[62] Beaven SW, Tontonoz P. Nuclear receptors in lipid metabolism: targeting the heart of dyslipidemia. Annu Rev Med 2006; 57: 31329.

[63] Miller AM, Wang H, Park O, et al. Anti-inflammatory and antiapoptotic roles of endothelial cell STAT3 in alcoholic liver injury. Alcohol Clin Exp Res 2012; 34(4): 719-25.

[64] Mukamal KJ, Jenny NS, Tracy RP, Siscovick DS. Alcohol consumption, interleukin-6 and apolipoprotein E genotypes, and concentrations of interleukin-6 and serum amyloid $\mathrm{P}$ in older adults. Am J Clin Nutr 2007; 86(2): 444-50.

[65] Tilg H, Diehl AM. Cytokines in alcoholic and nonalcoholic steatohepatitis. N Engl J Med 2000; 343(20): 1467-76.

[66] Haga S, Terui K, Zhang HQ, et al. Stat3 protects against Fasinduced liver injury by redox-dependent and -independent mechanisms. J Clin Invest 2003; 112(7): 989-98.

[67] Taub R. Hepatoprotection via the IL-6/Stat3 pathway. J Clin Invest 2003; 112(7): 978-80.

[68] Horiguchi N, Wang L, Mukhopadhyay P, et al. Cell typedependent pro- and anti-inflammatory role of signal transducer and activator of transcription 3 in alcoholic liver injury. Gastroenterology 2008 ; 134(4): 1148-58.

[69] Eberle D, Hegarty B, Bossard P, Ferre P, Foufelle F. SREBP transcription factors: master regulators of lipid homeostasis. Biochimie 2004; 86(11): 839-48

[70] Zhou G, Myers R, Li Y, et al. Role of AMP-activated protein kinase in mechanism of metformin action. J Clin Invest 2001; 108(8): 1167-74.

[71] Xu A, Wang Y, Keshaw H, Xu LY, Lam KS, Cooper GJ. The fatderived hormone adiponectin alleviates alcoholic and nonalcoholic fatty liver diseases in mice. J Clin Invest 2003; 112(1): 91-100.

[72] Chen C, Dudenhausen EE, Pan YX, Zhong C, Kilberg MS. Human CCAAT/enhancer-binding protein beta gene expression is activated by endoplasmic reticulum stress through an unfolded protein response element downstream of the protein coding sequence. J Biol Chem 2004; 279(27): 27948-56.

[73] Poli V. The role of C/EBP isoforms in the control of inflammatory and native immunity functions. J Biol Chem 1998; 273(45): 2927982.

[74] He L, Ronis MJ, Badger TM. Ethanol induction of class I alcohol dehydrogenase expression in the rat occurs through alterations in CCAAT/enhancer binding proteins beta and gamma. J Biol Chem 2002; 277(46): 43572-7.

[75] Husain K, Somani SM. Interaction of exercise training and chronic ethanol ingestion on hepatic and plasma antioxidant system in rat. $\mathrm{J}$ Appl Toxicol 1997; 17(3): 189-94.

[76] Lu Y, Cederbaum AI. CYP2E1 and oxidative liver injury by alcohol. Free Radic Biol Med 2008; 44(5): 723-38.

[77] Ioannou GN, Dominitz JA, Weiss NS, Heagerty PJ, Kowdley KV. The effect of alcohol consumption on the prevalence of iron overload, iron deficiency, and iron deficiency anemia. Gastroenterology 2004; 126(5): 1293-301.

[78] Tsukamoto H, Lin M, Ohata M, Giulivi C, French SW, Brittenham G. Iron primes hepatic macrophages for NF-kappaB activation in alcoholic liver injury. Am J Physiol 1999; 277(6 Pt 1): G1240-50.

[79] Xiong S, She H, Sung CK, Tsukamoto H. Iron-dependent activation of NF-kappaB in Kupffer cells: a priming mechanism for alcoholic liver disease. Alcohol 2003; 30(2): 107-13.

[80] Feierman DE, Winston GW, Cederbaum AI. Ethanol oxidation by hydroxyl radicals: role of iron chelates, superoxide, and hydrogen peroxide. Alcohol Clin Exp Res 1985; 9(2): 95-102.

[81] Heritage ML, Murphy TL, Bridle KR, Anderson GJ, Crawford DH, Fletcher LM. Hepcidin regulation in wild-type and Hfe knockout mice in response to alcohol consumption: evidence for an alcohol- induced hypoxic response. Alcohol Clin Exp Res 2009; 33(8): 1391-400.

[82] Zakhari S. Overview: how is alcohol metabolized by the body? Alcohol Res Health 2006; 29(4): 245-54.

[83] Nguyen T, Nioi P, Pickett CB. The Nrf2-antioxidant response element signaling pathway and its activation by oxidative stress. $\mathrm{J}$ Biol Chem 2009; 284(20): 13291-5.

[84] Niture SK, Kaspar JW, Shen J, Jaiswal AK. Nrf2 signaling and cell survival. Toxicol Appl Pharmacol 2010; 244(1): 37-42

[85] Vargas MR, Johnson JA. The Nrf2-ARE cytoprotective pathway in astrocytes. Expert Rev Mol Med 2009; 11: e17.

[86] Kietzmann T, Gorlach A. Reactive oxygen species in the control of hypoxia-inducible factor-mediated gene expression. Semin Cell Dev Biol 2005; 16(4-5): 474-86.

[87] Chandel NS, McClintock DS, Feliciano CE, et al. Reactive oxygen species generated at mitochondrial complex III stabilize hypoxiainducible factor-1alpha during hypoxia: a mechanism of $\mathrm{O} 2$ sensing. J Biol Chem 2000; 275(33): 25130-8.

[88] Furuta E, Pai SK, Zhan R, et al. Fatty acid synthase gene is upregulated by hypoxia via activation of Akt and sterol regulatory element binding protein-1. Cancer Res 2008; 68(4): 1003-11.

[89] Ohashi N, Katsurada A, Miyata K, et al. Activation of reactive oxygen species and the renin-angiotensin system in IgA nephropathy model mice. Clin Exp Pharmacol Physiol 2009; 36(5-6): 50915.

[90] Hsieh TJ, Zhang SL, Filep JG, Tang SS, Ingelfinger JR, Chan JS. High glucose stimulates angiotensinogen gene expression via reactive oxygen species generation in rat kidney proximal tubular cells. Endocrinology 2002; 143(8): 2975-85.

[91] Aroor AR, Shukla SD. Binge ethanol intake in chronically exposed rat liver decreases LDL-receptor and increases angiotensinogen gene expression. World J Hepatol 2011; 3(9): 250-5.

[92] Husain K, Ferder L, Ansari RA, Lalla J. Chronic ethanol ingestion induces aortic inflammation/oxidative endothelial injury and hypertension in rats. Hum Exp Toxicol 2011; 30(8): 930-9.

[93] Husain K, Vazquez M, Ansari RA, Malafa MP, Lalla J. Chronic alcohol-induced oxidative endothelial injury relates to angiotensin II levels in the rat. Mol Cell Biochem 2008; 307(1-2): 51-8.

[94] Ansari RA, Clark MA, Eds. Regulation of angiotensinogen gene after ethanol in hepatocytes. 50th Anniversary and Annual Meeting, Society of Toxicology; 2011 March 6-10; Washington D.C. 2011.

[95] Ansari RA, Rizvi SAA, Clark MA, Eds. Angiotensinogen gene regulation after ethanol exposure in hepatocytes. World Congress on Gastroenterology and Urology; 2012 March 12-14; Omaha, NE: OMICS 2012.

[96] Nibu Y, Tanimoto K, Takahashi S, Ono H, Murakami K, Fukamizu A. A cell type-dependent enhancer core element is located in exon 5 of the human angiotensinogen gene. Biochem Biophys Res Commun 1994; 205(2): 1102-8.

[97] Kumar A, Li Y, Patil S, Jain S. A haplotype of the angiotensinogen gene is associated with hypertension in african americans. Clin Exp Pharmacol Physiol 2005; 32(5-6): 495-502.

[98] Narayanan CS, Cui Y, Kumar A. DBP binds to the proximal promoter and regulates liver-specific expression of the human angiotensinogen gene. Biochem Biophys Res Commun 1998; 251(1): 388-93.

[99] Cui Y, Narayanan CS, Zhou J, Kumar A. Exon-I is involved in positive as well as negative regulation of human angiotensinogen gene expression. Gene 1998; 224(1-2): 97-107.

[100] Sherman CT, Brasier AR. Role of signal transducers and activators of transcription 1 and -3 in inducible regulation of the human angiotensinogen gene by interleukin-6. Mol Endocrinol 2001; 15(3): 441-57.

[101] Brasier AR, Li J. Mechanisms for inducible control of angiotensinogen gene transcription. Hypertension 1996; 27(3 Pt 2): 465-75.

[102] Narayanan CS, Cui Y, Kumar S, Kumar A. cAMP increases the expression of human angiotensinogen gene through a combination of cyclic AMP responsive element binding protein and a liver specific transcription factor. Mol Cell Biochem 2000; 212(1-2): 81-90.

[103] Yanai K, Hirota K, Taniguchi-Yanai K, et al. Regulated expression of human angiotensinogen gene by hepatocyte nuclear factor 4 and chicken ovalbumin upstream promoter-transcription factor. J Biol Chem 1999; 274(49): 34605-12.

[104] Jain S, Li Y, Patil S, Kumar A. A single-nucleotide polymorphism in human angiotensinogen gene is associated with essential hyper- 
tension and affects glucocorticoid induced promoter activity. J Mol Med 2005; 83(2): 121-31.

[105] Narayanan CS, Cui Y, Zhao YY, Zhou J, Kumar A. Orphan receptor Arp-1 binds to the nucleotide sequence located between TATA box and transcriptional initiation site of the human angiotensinogen gene and reduces estrogen induced promoter activity. Mol Cell Endocrinol 1999; 148(1-2): 79-86.

[106] Gabay C, Kushner I. Acute-phase proteins and other systemic responses to inflammation. N Engl J Med 1999; 340(6): 448-54.
[107] Morgan L, Broughton Pipkin F, Kalsheker N. Angiotensinogen: molecular biology, biochemistry and physiology. Int J Biochem Cell Biol 1996; 28(11): 1211-22.

[108] Moshage H. Cytokines and the hepatic acute phase response. J Pathol 1997; 181(3): 257-66.

[109] Acres OW, Satou R, Navar LG, Kobori H. Contribution of a nuclear factor-kappaB binding site to human angiotensinogen promoter activity in renal proximal tubular cells. Hypertension 2011; 57(3): 608-13.

Received: April 18, 2012

Revised: May 30, 2012

Accepted: June 04, 2012

(C) Ansari et al.; Licensee Bentham Open.

This is an open access article licensed under the terms of the Creative Commons Attribution Non-Commercial License (http://creativecommons.org/licenses/ by-nc/3.0/) which permits unrestricted, non-commercial use, distribution and reproduction in any medium, provided the work is properly cited. 